\title{
What Does Your Profile Picture Say About You? The Accuracy of Thin-Slice Personality Judgments from Social Networking Sites Made at Zero-Acquaintance
}

\author{
Mark Turner and Natalie Hunt \\ Department of Psychology, University of Portsmouth, Portsmouth, United Kingdom \\ Mark.Turner@port.ac.uk, Natalie.Hunt@myport.ac.uk
}

\begin{abstract}
The study investigates impressions formed through social networking sites, specifically the initial judgments we make of others when first momentarily exposed to their photograph. The personality characteristics of 52 Female Facebook profile owners were evaluated by a group of raters who briefly viewed the current profile picture of each person. Analysis revealed consensus between raters when judging personality attributes, although self-other agreement was low: raters' judgments correlated with profile owners' judgments of their own personality for only 2 out of the 10 attributes examined. Profile owners perceived as more physically attractive were rated more positively on other personality attributes. Smiling, and being alone or with others in a profile picture was also demonstrated to have a significant impact on personality assessments. It was concluded that whilst profile pictures can strongly influence how we judge others, such initial judgments are not highly likely to be accurate.
\end{abstract}

Keywords: First Impressions, Personality, Facebook, Thin-slice judgments.

\section{Introduction}

The popularity of Social Networking Sites (SNSs) has seen a change in the way people meet and interact with one another. In some cases, impressions of new acquaintances may now be formed initially online rather than face-to-face. However, current academic research has provided contradictory evidence concerning the accuracy of judgments based on SNS profiles and it is unclear how much influence personal images posted by users have on impressions formed.

It is known that first impressions can be formed rapidly from facial images and that this tendency is both spontaneous and continuous [1, 2]. Nevertheless, some authors [3] have suggested that online social networks contain a different set of implied norms that guide self-presentation. For example, Facebook users are known to use images to create desired impressions that promote the self as being highly social [4]. Since SNS users have the ability to selectively control personal details and images displayed online, this may lead to the creation of viewers' perceptions that are inconsistent with a target's true offline self. This is evidenced by research examining the concordance between impressions formed from online personal profiles with those offline which 
suggests only a weak correlation to exist between the likeability of target individuals judged from their Facebook profiles compared to evaluations of the same individuals following face-to-face conversations [5].

When several observers are asked to judge the personality traits of people with whom they are not acquainted, it has been demonstrated that high levels of consensus between raters can be achieved whether based on visual cues [6] or auditory cues only [7], and when judgments are made from very brief periods of exposure ('thin slices') to the target individual [8].

It is also known that observers' impressions of a target individual's personality can be consistent with the target person's view of their own personality [9]. Levels of selfother agreement between targets and observers are known to improve when more overt, highly-visible traits such as extraversion are evaluated; or more desirable traits (e.g. intelligence, conscientiousness) as opposed to neutral or pejorative traits (e.g. unreliable, arrogant) are considered [10]. Whilst agreement between self-ratings and observer impressions are sometimes assumed to provide a proxy measure for the accuracy of first impression judgments, e.g., [11] other authors have argued that selfother agreement cannot be used as a criterion for accuracy since self-reports may provide an unreliable indicator of true personality [2].

When considering impressions formed from Facebook profiles, previous studies $[11,12]$ report good convergence for personality ratings made by close acquaintances from Facebook profile pages when browsing is restricted to key information, although the accuracy of judgments made at zero-acquaintance by strangers varies considerably between different personality traits. Stecher and Counts [13] found personality judgments for online profiles to be equally as accurate from condensed profiles showing limited information, as the impressions formed from seeing a user's full profile. This would suggest that SNS users neither seek nor normally require much information in order to make initial judgments of others.

Ivcevic and Ambady [14] compared raters' personality judgments of target individuals either based on full Facebook profile pages or based on other single sources of online information, such as profile pictures, interests or personal preferences. Consensus between raters when making personality judgments was found to be greatest when based on profile pictures alone compared to all other sources of user information available through Facebook, whilst personality ratings judged from full profile pages were most highly correlated with ratings of profile pictures. This suggests profile pictures to be a decisive factor when first forming impressions of others online.

However, Steele et al [15] demonstrated that the level of impression agreement between observer ratings of profile owners' personalities may also be dependent on the style of photograph used on a profile page, with agreement being greater for profile images that depicted the owner smiling or outdoors. Similarly, Naumann et al [16] showed that judgment accuracy can be manipulated by requiring participants to pose with neutral facial expressions compared to posing with spontaneous expressions. This suggests freedom to choose one's appearance may more readily convey cues to true personality on one hand, but that such cues are also subject to misinterpretation.

Haferkamp et al [17] observed that males and females use social networking sites for different reasons. They suggest that men are more inclined to look for friends or 
start new acquaintances, whereas females are more likely to use social networking sites to compare themselves to other people and to seek out information. Such differences in motivations for use may also consequently lead to differences in the forms of information which men and women rely on when making judgments through SNSs.

A further factor when forming impressions of others is physical appearance. Previous research has identified that more attractive people are generally assumed by observers to have better social skills and are typically rated as more likeable and thought to possess other positive personality traits than less attractive people $[18,19]$. When a person is smiling they are also seen to be more beautiful and are rated more generously on other personality traits and general virtuousness [20], whilst both male and female Facebook users have been shown to be more willing to initiate friendships with opposite-sex profile owners with more attractive profile pictures [21].

The current study therefore investigates both consensus and agreement for first impressions formed from profile pictures by male and female observers when judging the personality characteristics of individuals with whom they are not acquainted. The influence of picture content and other owner characteristics such as perceived level of attractiveness on personality judgments are also explored.

\section{Method}

\subsection{Participants}

Female Facebook profile owners ( $N=52$; mean age, 19.4 yrs; SD, 1.6) who consented to their current profile picture being viewed by others, completed a questionnaire regarding their general use and behavior on SNSs, questions regarding their choice of profile picture and a 10-item self-evaluation of personality.

A group of 10 observers (5 males and 5 females) of similar age and background to the female participants then viewed all 52 profile pictures and were asked to complete the same questionnaire evaluation of personality for each profile owner.

All profile owners were experienced users of Facebook with $71 \%$ of the sample reporting checking the site on average, 4 or more times per day, and $67 \%$ reporting having 400 or more friends on the site. The mean number of pictures participants reported currently having in their 'Profile Pictures' album was 64.4 (SE, 7.0).

Observers were also selected to be experienced Facebook users with $100 \%$ of raters reporting checking the site at least 4 or more times per day and having an average of 561 friends (range, 200 to 833). None of the 10 observers were previously acquainted with any of the 52 profile owners, prior to the study.

\subsection{Measures}

Participants were asked to write a brief open-text explanation for choosing their current profile picture and to rate on a 7-point scale (where a score of 1 represented 'extremely unlikely' and a score of 7 represented 'extremely likely') the extent to which they might select different types of images as their main profile pictures (e.g. "Full body picture of yourself alone"). Questions concerning the types of profile 
picture participants were likely to use were derived from the categorization of picture types identified by Steele et al [15].

The personality characteristics of each profile owner were assessed using an adapted version of Bond's dimensions used in perceiving peers [22]. This involved the rating of 10 bipolar objectives (e.g., Nervous - Calm) on a 7-point scale where a higher score was associated with the more positive attribute.

\subsection{Procedure}

Consistent with the minimum display durations used in other thin-slice judgment studies e.g., [1], [8], pictures were serially presented on separate slides for a set time of 10 seconds. Pictures were shown abstracted from any other Facebook information about the profile owner, with a blank slide being shown between pictures during which personality judgments were made. Where pictures contained more than one person, the position of the target individual was stated below the picture. The presentation duration of each picture was controlled by a computer with a researcher present to ensure the task was completed correctly. No discussion of the photographic content of pictures was permitted between the researcher and observers. Observers were allowed as much time as they required to complete the personality evaluation for each picture, before moving on to the next picture. This procedure resulted in a total of 5,200 thin-slice personality evaluations being made across 10 different personality attributes and 10 different observers.

\section{$3 \quad$ Results}

\subsection{Choice of Profile Picture}

Four common response types were identified in participants' explanations for choosing their current profile picture, with most common reason given by participants being: $44 \%(n=23)$ because of who was in the photograph (e.g. friends or family); $29 \%$ $(n=15)$ because it reminded them of a good memory; $21 \%(n=11)$ because they felt they looked good in the picture; and, $15 \%(n=8)$ because they had wished to update their picture.

In order to statistically compare whether participants were more likely to consider using some types of profile pictures more than others, a one-way repeated measures ANOVA was performed on the likelihood ratings for choosing different photograph types $\left(F(10,510)=55.83, p<.001, \eta_{p}^{2}=.52\right)$. These data showed the likelihood of choosing some profile pictures to be higher than others: participants were most likely to use a picture of themselves with others as their profile picture, a picture of themselves smiling, or a picture of themselves making eye contact with the camera; and least likely to use pictures that did not include themselves such as drawings, pictures of landscapes, animals, other objects (Table 1). 
Table 1. Mean likelihood rating of selecting 11 different image types as a profile picture. Possible score range, 1-7; higher scores indicate greater likelihood of selection.

\begin{tabular}{lcc}
\hline Profile Picture Content & Mean & SD \\
\hline Picture of yourself with others & 6.38 & 0.93 \\
Picture of yourself smiling & 5.56 & 1.58 \\
Picture of yourself making eye contact with the camera & 5.46 & 1.26 \\
Picture of yourself doing an activity & 5.06 & 1.73 \\
Portrait (face only) picture of yourself alone & 4.38 & 2.16 \\
Picture of yourself with face covered (e.g. wearing sunglasses) & 3.81 & 1.92 \\
Full body picture of yourself alone & 3.69 & 2.06 \\
Picture of a pet or other animal & 3.08 & 1.94 \\
Picture of a landscape & 2.17 & 1.77 \\
Picture of another object & 1.96 & 1.47 \\
Drawing or pattern & 1.63 & 1.33 \\
\hline
\end{tabular}

\subsection{Observer Agreement and Self-observer Agreement when Judging 10 Personality Characteristics from Current Profile Pictures}

Observer agreement (consensus) was calculated for each type of personality judgment using intraclass correlations (ICC) with a two-way random effects model. Both single measures, ICC $(2,1)$ and average measures, ICC $(2, \mathrm{k})$ of observer consensus were calculated (Table 2). These data suggest a good level of consensus between raters in their evaluation of profile pictures based on 10-second exposures (Cronbach's Alpha values $>0.70$ ). Observer agreement was greatest for attractiveness and other overt attributes typically associated with extraversion (e.g., friendly, outgoing, confident). Observer agreement was lowest when judging calmness and reliability.

Self-other agreement was examined by correlating each profile owners' selfevaluation with aggregated observer ratings for each of the 10 personality attributes. Correlations were calculated using personality judgments averaged across all 10 raters, and separately for the 5 male and 5 female raters.

Significant relationships were found for only 2 of the 10 personality attributes: self and observer ratings were positively correlated for sensitivity $(\mathrm{r}=.58)$ and loudness $(\mathrm{r}=.32)$ suggesting observers' ratings were more likely to co-vary with profile owners' own judgments of these attributes. Self-other agreement estimates were largely consistent across genders with the exception of the intelligence attribute; male raters' evaluations of intelligence correlated positively with female profile owners' ratings of their own intelligence $(r=.28)$ but a corresponding relationship was not found in the case of female raters.

For the remaining personality attributes no significant relationships were found such that raters' judgments did not agree with the profile owners' own evaluations of their personality; this suggests impression ratings for these attributes can be assumed to be inaccurate. 
Table 2. Intraclass correlations for single (ICC 2,1) and averaged (ICC 2,k) measures of observer agreement (consensus) and Pearson (r) correlation coefficients between self-ratings and averaged observer ratings for 10 personality attributes $(* \mathrm{p}<.05 * * \mathrm{p}<.01 ; * * * \mathrm{p}<.001)$

\begin{tabular}{|c|c|c|c|c|c|}
\hline \multirow[t]{2}{*}{ Attribute } & \multicolumn{2}{|c|}{ Consensus } & \multicolumn{3}{|c|}{ Self-Other Agreement (r) } \\
\hline & $\operatorname{ICC}(2,1)$ & $\operatorname{ICC}(2, \mathrm{k})$ & $\begin{array}{c}\text { All } \\
\text { Raters }\end{array}$ & $\begin{array}{c}\text { Female } \\
\text { Raters }\end{array}$ & $\begin{array}{l}\text { Male } \\
\text { Raters }\end{array}$ \\
\hline Nervous-Calm & $.23 * * *$ & $.75 * * *$ & .20 & .12 & .26 \\
\hline Insecure-Confident & $.42 * * *$ & $.88 * * *$ & -.11 & -.08 & -.12 \\
\hline Shy-Outgoing & $.43 * * *$ & $.88 * * *$ & .16 & .20 & .11 \\
\hline Unattractive-Attractive & $.54 * * *$ & $.92 * * *$ & -.01 & -.01 & -.00 \\
\hline Unfriendly-Friendly & $.42 * * *$ & $.88 * * *$ & .24 & .22 & .23 \\
\hline Insensitive-Sensitive & $.28 * * *$ & $.80 * * *$ & $.58 * *$ & $.56^{* *}$ & $.50 * *$ \\
\hline Careless-Perfectionist & $.33 * * *$ & $.83 * * *$ & -.03 & -.03 & -.02 \\
\hline Quiet-Loud & $.37 * * *$ & $.85 * * *$ & $.32 *$ & $.31 *$ & $.29 *$ \\
\hline Unreliable-Reliable & $.20 * * *$ & $.72 * * *$ & .15 & .13 & .14 \\
\hline Unintelligent-Intelligent & $.28 * * *$ & $.80 * * *$ & .24 & .17 & $.28 *$ \\
\hline
\end{tabular}

\subsection{Observers' Judgments of Attractiveness with Other Personality Attributes}

To examine the relationships between the 10 raters' judgments of the attractiveness of each female profile owner and their judgment of other traits of each female, Pearson correlation coefficients were calculated separately for both male and female raters (Table 3).

For female raters, judgments of attractiveness were positively correlated with calmness $(\mathrm{r}=.49)$, confidence $(\mathrm{r}=.53)$, outgoingness $(\mathrm{r}=.36)$, friendliness $(\mathrm{r}=.56)$ and perfectionism $(\mathrm{r}=.51)$. Furthermore, significant correlations were found for attractiveness with reliability $(\mathrm{r}=.38)$ and intelligence $(\mathrm{r}=.45)$ whereby profile owners who were rated as more attractive were thought to be more reliable and intelligent.

For male raters, a similar pattern of significant relationships was found. Perceived attractiveness was positively correlated with calmness $(r=.59)$, confidence $(r=.65)$, outgoingness $(r=.57)$, friendliness $(r=.43)$ and perfectionism $(r=.60)$.

Taken together, these findings suggest that both male and female raters who thought the target person was more attractive assumed them to have more positive attributes. However, only female raters showed judgments which associated attractiveness with reliability and intelligence. 
Table 3. Correlations between perceived attractiveness and other positive traits in male and female raters. $* * \mathrm{p}<.01 ; * \mathrm{p}<.05$ (2-tailed).

\begin{tabular}{lll}
\hline Attribute & Male & Female \\
\hline Calm & $.59^{* *}$ & $.49^{* *}$ \\
Confident & $.65^{* *}$ & $.53^{* *}$ \\
Outgoing & $.57^{* *}$ & $.36^{* *}$ \\
Friendly & $.43^{*}$ & $.56^{* *}$ \\
Sensitive & .21 & .27 \\
Perfectionist & $.61^{* *}$ & $.51^{* *}$ \\
Loud & -.15 & -.08 \\
Reliable & .07 & $.38^{* *}$ \\
Intelligent & .25 & $.45^{* *}$ \\
\hline
\end{tabular}

\subsection{Effect of Smiling and Non-smiling Pictures on Observers' Judgments}

Differences in observers' ratings of participants who smiled and did not smile in their profile picture were analyzed for each of the 10 personality attributes using one-way independent groups MANOVA. The multivariate effect of picture type was found to be significant, $\mathrm{F}(10,41)=2.86, \mathrm{p}=.009$, Wilks' $\lambda=.589$.

Significant univariate effects were found for the ratings of friendliness, sensitivity and reliability, whereby profile owners were judged to be friendlier, more sensitive and more reliable if they were smiling in their profile picture compared to nonsmiling pictures. No significant differences were found for the remaining 7 personality characteristics (Table 4).

Table 4. Univariate $F$ test comparions for effect of smiling $(n=35)$ and not smiling $(n=17)$ in a profile picture on personality attribute judgments made by observers. Possible score range, 1-7; higher scores tend towards right attribute pole.

\begin{tabular}{lcccccc}
\hline \multirow{2}{*}{ Attribute } & \multicolumn{2}{c}{ Smiling } & \multicolumn{2}{c}{ Not Smiling } & \multirow{2}{*}{ F value } & \multirow{2}{*}{ Sig. } \\
\cline { 2 - 5 } & $\mathrm{M}$ & $\mathrm{SD}$ & $\mathrm{M}$ & $\mathrm{SD}$ & & $.13 \mathrm{~ns}$ \\
\hline Nervous-Calm & 4.48 & 0.71 & 4.15 & 0.67 & 2.40 & $.69 \mathrm{~ns}$ \\
Insecure-Confident & 4.70 & 0.89 & 4.59 & 1.10 & 0.16 & $.51 \mathrm{~ns}$ \\
Shy-Outgoing & 4.52 & 1.06 & 4.31 & 1.04 & 0.43 & $.59 \mathrm{~ns}$ \\
Unattractive-Attractive & 4.03 & 0.99 & 3.85 & 1.40 & 0.30 & .001 \\
Unfriendly-Friendly & 5.14 & 0.59 & 4.14 & 0.91 & 22.17 & .007 \\
Insensitive-Sensitive & 4.77 & 0.70 & 4.21 & 0.59 & 7.82 & $.93 \mathrm{~ns}$ \\
Careless-Perfectionist & 4.45 & 0.81 & 4.47 & 0.89 & 0.01 & $.91 \mathrm{~ns}$ \\
Quiet-Loud & 3.97 & 0.98 & 3.94 & 0.86 & 0.01 & .001 \\
Unreliable-Reliable & 4.86 & 0.59 & 4.29 & 0.49 & 11.31 & $.09 \mathrm{~ns}$ \\
Unintelligent-Intelligent & 4.73 & 0.75 & 4.34 & 0.74 & 3.01 & \\
\hline
\end{tabular}




\subsection{Effect of Individual or Group Pictures on Observers' Judgments}

A further independent groups MANOVA was conducted to analyze differences in judgments of the 10 personality attributes when profile owners either posed individually ('alone' condition) or as a part of a group ('with others' condition) in their profile picture. The multivariate effect of picture type was found to be significant, $\mathrm{F}(10,41)=3.55, \mathrm{p}=.002$, Wilks' $\lambda=.536$.

Significant univariate effects were found for observers' ratings of calmness, outgoingness, friendliness and loudness, whereby participants were judged to be significantly calmer, more outgoing, friendlier and less quiet when other people were present in their profile picture. No differences were found for the remaining 6 personality attributes.

Table 5. Univariate $F$ tests of being alone $(n=19)$ or with others $(n=33)$ in a profile picture on personality attribute judgments made by observers. Possible score range, 1-7; higher scores tend towards right attribute pole.

\begin{tabular}{lcccccc}
\hline \multirow{2}{*}{ Attribute } & \multicolumn{2}{c}{ Alone } & \multicolumn{2}{c}{ With Others } & \multirow{2}{*}{ F value } & \multirow{2}{*}{ Sig. } \\
\cline { 2 - 5 } & $\mathrm{M}$ & $\mathrm{SD}$ & $\mathrm{M}$ & $\mathrm{SD}$ & & \\
\hline Nervous-Calm & 4.05 & 0.82 & 4.56 & 0.57 & 6.87 & .01 \\
Insecure-Confident & 4.35 & 1.20 & 4.86 & 0.74 & 3.59 & $.06 \mathrm{~ns}$ \\
Shy-Outgoing & 3.90 & 1.04 & 4.77 & 0.92 & 9.84 & .003 \\
Unattractive-Attractive & 3.71 & 1.31 & 4.13 & 1.01 & 1.65 & $.20 \mathrm{~ns}$ \\
Unfriendly-Friendly & 4.32 & 0.97 & 5.10 & 0.63 & 12.10 & .001 \\
Insensitive-Sensitive & 4.43 & 0.73 & 4.67 & 0.69 & 1.39 & $.24 \mathrm{~ns}$ \\
Careless-Perfectionist & 4.61 & 0.73 & 4.37 & 0.69 & 0.96 & $.33 \mathrm{~ns}$ \\
Quiet-Loud & 3.59 & 0.94 & 4.17 & 0.87 & 4.97 & .03 \\
Unreliable-Reliable & 4.50 & 0.52 & 4.77 & 0.66 & 2.24 & $.14 \mathrm{~ns}$ \\
Unintelligent-Intelligent & 4.57 & 0.63 & 4.62 & 0.84 & 0.07 & $.79 \mathrm{~ns}$ \\
\hline
\end{tabular}

\section{Discussion}

A key finding of the current study was that individuals who were seen as more attractive were rated more generously on other personality attributes. This finding is consistent with previous research on attractiveness [18, 19] suggesting that attractive individuals are seen to possess more desirable personality traits in the context of $\mathrm{Fa}$ cebook profile photographs, and that physical appearance is also an important criterion when forming impressions of a new person through social networking sites.

Good agreement was found between observers when evaluating the traits of profile owners in the present study, suggesting strangers can readily form a consensus opinion when encountering new individuals, even at very brief exposure durations. 
It is important to note however, that although the evaluation of two attributes; sensitivity and loudness showed some similarity between observer and self-ratings, overall personality traits were not judged with great accuracy. Additionally, neither male nor female observers were found to be more accurate when judging aspects of unknown females' character. This implies that, from brief exposure to a profile picture alone, it may not be possible to gain sufficient information about a person to make accurate assumptions of their personality and intelligence. This finding is inconsistent with some previous research of first impersonation formation on Facebook [11, 12] which used more involved browsing tasks, suggesting that when viewing an online profile, people may need more time to consider other aspects of a person's profile, or require additional information to make a better judgment of them.

In relation to the influence of attractiveness on personality judgements, the only two traits found not to be influenced by attractiveness were loudness and sensitivity, which were also the only two traits that were found to be assessed with a significant degree of self-observer agreement. A potential explanation for these findings could be that the influence of attractiveness on personality judgements would lead to inaccuracy in personality judgements. It could be suggested that too much weight is placed on attractiveness during impression formation leading individuals to make less accurate judgments, although this does not preclude other explanations of these data.

Pictures of profile owners who were smiling were seen to be more reliable, sensitive and friendly than if they were not smiling. Similarly, where pictures contained more than one person, profile owners were rated as less quiet, more friendly, calm and outgoing. This would suggest that smiling and the presence of others in a profile picture, in addition to the profile owner's level of attractiveness, positively influences a viewer's perception of the individual.

Given that Facebook users are not naïve to the public nature of the site, an implication of the current findings is that individuals are likely to choose a profile picture based on the knowledge that their selection will have an influence on the way others judge them. For example, it was found in the current study that some profile owners feel it is important to choose an attractive profile picture, in order to give a more positive impression of themselves. This in turn may lead to a further potential source of inaccuracy when evaluating personality attributes since individuals seek to present their best rather than true self $[3,4]$.

Previous research exploring exposure time and the accuracy of first impressions formed face-to-face suggests an optimum level of accuracy can be achieved between 20 to 60 seconds when judging personality [1], [8]. In the current study, sub-optimum exposure times to each picture of 10 seconds were used. Whilst this was partly done for practical reasons to limit observer fatigue, this also served to address the theoretical issue of whether impression accuracy can be achieved more rapidly through the structure and implicit conventions that determine the format and suitability of profile pictures within the Facebook community. Self-evidently, increasing exposure time to each picture could, in turn, have led to different accuracy predictions. It remains to be established what a true representation of the time to form accurate opinions from $\mathrm{Fa}$ cebook profile pictures might be. 
It can be concluded from the current study that the content of profile pictures can impact on the judgments others make of profile owners featured within the photographs. Specifically, personal attractiveness, smiling, and being in the presence of others leads to more positive evaluations of a profile owner from their main profile picture, which may not necessarily lead to accurate representations of the individual's true character. This effect held regardless of whether same sex or different sex evaluations were used in the assessment of the profile owner.

\section{References}

1. Ambaby, N., Rosenthal, R.: Half a minute: Predicting teacher evaluations form thin slices of nonverbal behaviour and physical attractiveness. Journal of Personality and Social Psychology 64(3), 431-441 (1993)

2. Rule, N., Ambady, N.: First impressions of the face: predicting success. Social and Personality Psychology Compass 4(8), 506-516 (2010)

3. Hum, N.J., Chamberlin, P.E., Hambright, B.L., Portwood, A.C., Schat, A.C., Bevan, J.L.: A picture is worth a thousand words: A content analysis of Facebook profile photographs. Computers in Human Behavior 27(5), 1828-1833 (2011)

4. Zhao, S., Grasmuck, S., Martin, J.: Identity construction on Facebook: Digital empowerment in anchored relationships. Computers in Human Behavior 24(5), 1816-1836 (2008)

5. Weisbuch, M., Ivcevic, Z., Ambady, N.: On being liked on the web and in the "real world": Consistency in first impressions across personal webpages and spontaneous behavior. Journal of Experimental Social Psychology 45(3), 573-576 (2009)

6. Kenny, D.A., Horner, C., Kashy, D.A., Chu, L.C.: Consensus at zero acquaintance: replication, behavioral cues, and stability. Journal of Personality \& Social Psychology 62(1), 88-97 (1992)

7. Holleran, S.E., Mehl, M.R., Levitt, S.: Eavesdropping on social life: The accuracy of stranger ratings of daily behavior from thin slices of natural conversations. Journal of Research in Personality 43, 660-672 (2009)

8. Carney, D.R., Colvin, C.R., Hall, J.A.: A thin slice perspective on the accuracy of first impressions. Journal of Research in Personality 41(5), 1054-1072 (2007)

9. Penton-Voak, I.S., Pound, N., Little, A.C., Perrett, D.I.: Personality judgments from natural and composite facial images: More evidence for a "kernel of truth" in social perception. Social Cognition 24(5), 607-640 (2006)

10. Kenny, D.A., West, T.V.: Similarity and agreement in self-and other perception: a metaanalysis. Personality and Social Psychology Review 14(2), 196-213 (2010)

11. Back, M.D., Stopfer, J.M., Vazire, S., Gaddis, S., Schmukle, S.C., Egloff, B., Gosling, S.D.: Facebook profiles reflect actual personality, not self-idealization. Psychological Science 21(3), 372-374 (2010)

12. Gosling, S.D., Gaddis, S., Vazire, S.: Personality impressions based on Facebook profiles. In: Proceedings of the International Conference on Weblogs and Social Media, Boulder, Colorado, U.S.A., March 26-28 (2007)

13. Stecher, K., Counts, S.: Thin slices of online profile attributes. In: Proceedings of the Second International ICWSM Conference, Seattle, Washington, U.S.A., March 30-April 2 (2008)

14. Ivcevic, Z., Ambady, N.: Personality impressions from identity claims on Facebook. Psychology of Popular Media Culture 1(1), 38-45 (2012) 
15. Steele, F., Evans, D.C., Green, R.K.: Is your profile picture worth 1000 words? Photo characteristics associated with personality impression agreement. In: Proceedings of the Third International ICWSM Conference, San Jose, California, U.S.A., May 17-20 (2009)

16. Naumann, L.P., Vazire, S., Rentfrow, P.J., Gosling, S.D.: Personality judgments based on physical appearance. Personality and Social Psychology Bulletin 35(12), 1661-1671 (2009)

17. Haferkamp, N., Eimler, S.C., Papadakis, A., Kruck, J.V.: Men are from Mars, women are from Venus? Examining gender differences in self-presentation on social networking sites. Cyberpsychology, Behavior and Social Networking 15(2), 91-98 (2012)

18. Dion, K., Berscheid, E., Walster, E.: What is beautiful is good. Journal of Personality and Social Psychology 24(3), 285-290 (1972)

19. Goldman, W., Lewis, P.: Beautiful is good: Evidence that the physically attractive are more socially skilful. Journal of Experimental Social Psychology 13(2), 125-130 (1977)

20. Reis, H.T., Wilson, I.M., Monestere, C., Bernstein, S., Clark, K., Seidl, E., Franco, M., Gioioso, E., Freeman, L., Radoane, K.: What is smiling is beautiful and good. European Journal of Social Psychology 20(3), 259-267 (1990)

21. Wang, S.S., Moon, S.I., Kwon, K.H., Evans, C.A., Stefanone, M.A.: Face off: Implications of visual cues on initiating friendship on Facebook. Computers in Human Behavior 26(2), 226-234 (2010)

22. Bond, M.H.: Dimensions used in perceiving peers: Cross-cultural comparisons of Hong Kong, Japanese, American and Filipino university students. International Journal of Psychology 14(1), 47-56 (1978) 